$\underline{\text { Review Article }}$

\title{
PRONIOSOMES: A VESICULAR DRUG DELIVERY SYSTEM
}

\author{
SARITHA M. ${ }^{1}$, SATYA PRAKASH PANDA ${ }^{2}$, SRAVANI BUDDHA ${ }^{3}$, P. V. KAMALA KUMARI ${ }^{4}$, Y. SRINIVASA RAO ${ }^{5}$ \\ Vignan Institute of Pharmaceutical Technology, Duvvada, Visakhaptanam \\ Email: chsaritha1975@gmail.com
}

Received: 04 Aug 2021, Revised and Accepted: 10 Oct 2021

\begin{abstract}
In the development of new dosage forms, drug delivery using nanotechnology is playing a vital role. Vesicular drug delivery systems have gained wide attention in the field of nanotechnology, such as niosomes, liposomes and proniosomes. Among the vesicular carriers, proniosomes are superior. Proniosomes are water-soluble carrier particles that are coated with surfactant so these are dry formulations. They are rehydrated to use on agitation in hot aqueous media within minutes to form niosomal dispersion immediately. Both hydrophilic and lipophilic drugscan be incorporated into these proteasomes. The physical stability problems of niosomes like aggregation, fusion and leaking are minimized in proniosomes, routes, such as oral, parenteral, dermal and transdermal, ocular, oral mucosal, vaginal, pulmonary, and intranasal. Proniosomes prolong the existence of the drug in the systemic circulation and finally reduces toxicity. This review focuses on different aspects of proniosomes such as preparation, characterization, in vitro drug release, entrapment efficiency, applications in the present scenario in the market and future
\end{abstract} trends.

Keywords: Proniosomes, Unilamellar, Multilamellar Vesicles, Hydrophobic, Hydrophilic

(c) 2021 The Authors. Published by Innovare Academic Sciences Pvt Ltd. This is an open-access article under the CC BY license (https://creativecommons.org/licenses/by/4.0/) DOI: https://dx.doi.org/10.22159/ijcpr.2021v13i6.1925 Journal homepage: https://innovareacademics.in/journals/index.php/ijcpr

\section{INTRODUCTION}

Novel drug delivery systems have made great progress in the field of nanotechnology. The main aim of novel drug delivery is to maintain a constant and effective drug level in the body and to minimize the side effects and to achieve drug targeting by using drug carriers [1]. Vesicular drug delivery i.e., vesicular carriers, shows a very promising role in permeability improvement and solubility enhancement and therefore, they can also improve the bioavailability of the drug by enhancing stability, absorption, targeting to site of action, which is actually the resultant of improved solubility, stability and permeability [2]. To encapsulate the drug vesicular drug delivery is one of the approaches e. g.: Liposomes, niosomes, transferosomes, pharmacosomes, and provesicles such as proniosomes and proliposomes [3]. These lipid vesicles can carry both hydrophilic drugs (by encapsulation) and hydrophobic drugs (in lipid domain) [4]. As these systems have a potential to carry a variety of drugs and have been widely used for various purposes, such as drug targeting, controlled release, and permeation enhancement of the drugs [5]. These systems have the advantage of increased solubility, increased membrane permeability leading to increased bioavailability, constant plasma concentration, improved patient compliance and improved efficacy [6]. In storage of niosomes and proniosomes, they exhibit good chemical stability, but aqueous suspension of niosome may exhibit problems of physical stability, such as aggregation, fusion, leaking of entrapped drugs [7].

Proniosomes are also termed as 'dry niosomes'. The encapsulation of drugs in the proniosomal vesicular structure maintains their systemic circulation, provides controlled release, enhances penetration in the targeted areas and reduces the toxic effects [8]. Proniosomes are dry, free-flowing formulations of the surfactant-coated carrier, which can be rehydrated by brief agitation in hot aqueous media within minutes. Both polar and non-polar, hydrophobic and hydrophilic drugs can be entrapped by proniosomes. Niosomes physical stability problems such as aggregation, fusion and leaking are minimized by proniosomes and they also provide additional convenience in transportation, distribution, storage, and dosing [9]. proniosomes prolongs the existence of the drug in the systemic circulation and finally reduces the toxicity. Proniosomes focuses on different aspects such as preparation, characterization, in vitro drug release, entrapment efficiency, applications [10]. This review will predominantly focus on functionality of proniosomes in the field of drug delivery and targeting.

Proniosomes are microscopic lamellar structures. They combine a non-ionic surfactant and cholesterol followed by hydration in aqueous media [11]. The surfactant molecule directs themselves such that the hydrophilic ends of the non-ionic surfactant orient outward, while the hydrophobic ends are in the opposite direction to form the bilayer. By these bilayer liposomes, proniosomes are also made. In proniosomes the bilayer is made of non-ionic surface-active agents [12].

Based on the method of preparation proniosomes are unilamellar or multi-lamellar. They are bilayered made of surfactants having its hydrophilic end exposed to the outside and inside of the vesicle, while the hydrophobic portion of both the layers face each other within the bilayer. The proteasomes hold both hydrophilic as well as hydrophobic drugs due to this reason. Hydrophilic drugs hold within the space enclosed in the vesicle and the hydrophobic drugs are embedded within the bilayer [13].

\section{Advantages of proniosomes [14]}

1. The surfactants and phospholipids in proniosomes help in penetration and with diffusion of the drug.

2. Proniosomes have additional convenience of dosing, storage, sterilization, transportation, and distribution.

3. Avoiding the problems of physical stability like fusion, aggregation, sedimentation and leakage on storage.

4. the shelf life of the drug is increased

5. Drug delivery with improved bioavailability can reduce side effects.

6. Entrapment of both hydrophilic and hydrophobic drugs.

7. By depot formulation, these show controlled and sustained release of drugs.

8. Biodegradable, biocompatible and non-immunogenic to the body.

9. Ease of storage and handling. 
10. The shape, size, composition, and fluidity of niosomes drug can be controlled.

11. They are osmotically active and stable, and also, they increase the stability of entrapped drug

12. They improve oral bioavailability of poorly absorbed drugs and enhance skin penetration of drugs.

13. They can be made to reach the site of action by oral, parenteral as well as topical routes.

\section{Types of proniosomes}

According to the method of preparation of proniosomes they are mainly of two types.

1. Dry granular proniosomes

a. Sorbitol-based proniosomes

b. Maltodextrin based proniosomes

2. Liquid crystalline proniosomes

\section{Dry granular proniosomes}

Dry granular proniosomes involves the coating of water-soluble carrier such as sorbitol and maltodextrin with surfactant resulting in the formation of a dry formulation in which thin film of surfactant covers each water soluble particle [15]. The vesicles must be prepared above the transition temperature of the surfactant being used

\section{Sorbitol based proniosomes}

Sorbitol based proniosomes is a dry formulation that involves sorbitol as a carrier, which is further coated with non-ionic surfactant and is used as a niosome by the addition of hot water followed by agitation. Sorbitol-based proniosomes are normally made by spraying surfactant mixture prepared in organic solvent onto the sorbitol powder and then evaporating the solvent. The process must be repeated till the surfactant coating is achieved [16].

\section{Maltodextrin based proniosomes}

Maltodextrin based proniosomes are prepared by slurry method Maltodextrins are easily soluble in water and are used as a carrier material in the formulation and hollow particle increases surface area also increases. Maltodextrin based proniosmes have potential application in delivery of hydrophilic or amphiphilic drugs.

\section{Liquid crystalline proniosomes}

The three ways in which the lipophilic chains of surfactants are transformed into a disordered liquid state called lyotropic liquid crystalline state when surfactant molecules come in contact with water

The three ways are as follows.

1) Increasing temperature at Kraft's point

2) Addition of solvents which dissolve lipids

3) Using both temperature and solvent.

\section{Method of preparation}

The different methods used for the preparation of proniosomes are as follows:
1. Slurry method
2. Hand shaking method
3. Spray coating method
4. Coacervation phase separation method

\section{Slurry method}

This method involves preparation of slurry in a round bottom flask using carrier (Maltodextrin or lecithin) and surfactant solution. The solvent is evaporated by rotating the flask attached to rotary flash evaporator at 60 to $70 \mathrm{rpm}$ at a temperature of $45 \pm 2{ }^{\circ} \mathrm{C}$ and at a pressure of $600 \mathrm{mmHg}$. The slurry is dried by applying vacuum overnight at room temperature to get free-flowing powder of proniosomes. The powder should be stored at $4{ }^{\circ} \mathrm{C}$ in a sealed container. The time required to produce proniosomes is independent of the ratio of carrier material to surfactant solution.

\section{Hand shaking method}

Cholesterol and surfactants are dissolved in organic solvents like ether, methanol or chloroform in a round bottom flask and the solvent is evaporated using a rotary evaporator leding to the formation of a thin layer of film on the walls of the round bottom flask. The film is hydrated with an aqueous phase with agitation.

\section{Spray coating method}

In this method, $100 \mathrm{ml}$ round bottom flask containing desired amount of carrier can be attached to rotary evaporator. The evaporator is evacuated and roataed in water bath under vacuum at $65-70{ }^{\circ} \mathrm{C}$ for $15-$ $20 \mathrm{~min}[17,18]$. Proniosomes are prepared by spraying surfactant in organic solvent onto a carrier/coating material (sorbitol) followed by evaporation of solvent. A thin film of surfactant is formed on the carrier and followed by hydration causes formation of multi-lamellar vesicles. The dried preparation is referred as proniosomal powder.

\section{Coacervation phase separation method}

It is a widely used method to prepare proniosmal gel. Accurately weighed quantities of drug, carrier (lecithin, lipid, cholesterol) and surfactants are taken in a clean and dry wide-mouthed glass beaker and solvent should be added to it. These ingredients are mixed well and warmed-over water bath at $60-70{ }^{\circ} \mathrm{C}$ for $5 \mathrm{~min}$ until the surfactant mixture dissolves completely. During the process care must be taken to prevent loss of any solvent due to evaporation. The aqueous phase is added to the mixture and warmed on water bath. Proniosomal gel is obtained on cooling the resultant solution overnight.

\section{Characterization on proniosomes}

\section{Particle size analysis}

\section{Scanning electron microscope}

Size distribution and surface morphology (smoothness, roundness and aggregates formation) of particles are studied by scanning electron microscopy (SEM).

\section{Optical microscopy}

The niosome suspension has to be placed over a glass slide and dried at room temperature and viewed under microscope, the dry, thin film of niosome suspension formed has to be observed in the formation of vesicles. The photomicrograph of the preparation is also obtained from the microscope by using a digital SLR camera [19]

\section{Measurement of Angle of repose}

The angle of repose of dry proniosomes powder was measured by a funnel method. In a fixed funnel, the proniosomes powder was poured. The powder flows down from the funnel to form a cone on the surface and the angle of repose was then calculated by measuring the height of the cone and the diameter of its base.

\section{Drug content}

Proniosomes equivalent to $100 \mathrm{mg}$ were taken in a standard volumetric flask. They were filled with $50 \mathrm{ml}$ methanol by shaking for $15 \mathrm{~min}$. The solution was diluted to $100 \mathrm{ml}$ with methanol. Then $10 \mathrm{ml}$ of this solution was diluted to $100 \mathrm{ml}$ with saline phosphate buffer at certain $\mathrm{pH}$. Aliquots were withdrawn and absorbance was measured at a certain wavelength and drug content was further calculated from the calibration curve [20].

\section{Measurement of zeta potential}

Zeta potential analysis is done in determining the colloidal properties of the prepared formulations. It is a measure of the particle charge, the larger the zeta potential absolute value the larger the amounts of surface charge. Logically, the zeta potential is an index for particle stability. In case of charged particles with an increase in zeta potential, 
the repulsive interactions also leading to the more stable particle formation with a more uniform size distribution.

\section{Measurement of vesicle size}

Mainly used for the characterization of vesicle size and shape. The proniosomal powder were hydrated with phosphate buffer (pH7.4) and subjected to bath sonication for $3 \mathrm{~min}$ and the resultant dispersion was used for determination of size [21] Vesicle size was measured by using particle size analyzer. The apparatus consists of a He-Ne laser beam of $632.8 \mathrm{~nm}$ focused with a minimum power of $5 \mathrm{Mw}$ using a Fourier lens (R-5) to a point at the center of small volume sample holding cell and multi-element detector. The samples were stirred with a stirrer before determining the vesicle size [22]

\section{Determination of entrapment efficiency}

Separation of unentrapped drug from the proniosomal suspension was carried out by a) exhaustive dialysis method and b) centrifugation method.

\section{Dialysis method}

In a dialysis tube the proniosomal suspension was taken, into which osmotic cellulose membrane was securely attached to one side, the dialysis tube was suspended at certain $\mathrm{pH}$ in $100 \mathrm{ml}$ saline buffer, which was stirred on a magnetic stirrer. The niosomal suspension and the unentrapped drug were separated into the medium through the osmotic cellulose membrane. After $6 \mathrm{~h}$ of exhaustive dialysis, optical density values were noted, and the estimation of the entrapped drug was carried out by UV spectrophotometric method [23].

\section{Centrifugation method}

The prepared proniosomes were separated from the entrapped drug by centrifugation. In this method hydrated proniosomes were centrifugation at $14000 \mathrm{rpm}$ for $5 \mathrm{~min}$ using the refrigerated centrifuge and the supernatant were analyzed for free drug content using UV spectrophotometry. Entrapment efficiency was calculated using the given formula,

Entrapment efficiency $=[($ Total drug loaded-free drug $) \times 100] /$ Total drug

\section{Fourier transform infrared (FT-IR) spectroscopy}

Infrared spectrum of the optimized proniosomes powder was obtained using Fourier transform infrared FT-IR) spectrophotometer by conventional potassium bromide pellets method. The scanning range between $4000-5000 \mathrm{~cm}^{-1}$.

\section{In vitro diffusion studies}

Skin permeation and in vitro diffusion studies for proniosomes can be done by various techniques such as Franz diffusion cell, dialysis tubing, keshary chien diffusion cell. In vitro skin permeation studies can be carried out using flank skin, dorsal skin of albino rabbit or female albino rat. Most commonly used method is Franz diffusion cell by taking Phosphate buffer as diffusion medium and temperature should be maintained at $37 \pm 0.5{ }^{\circ} \mathrm{C}$. An aliquot of $5 \mathrm{ml}$ was collected at predetermined time intervals and replaced with fresh phosphate buffer to maintain constant volume. Samples were analyzed for UV spectroscopy.

\section{In vitro drug release}

It can be achieved by using dialysis tubing. The proniosomes is placed in prewashed dialysis tubing which is sealed. The proniosomal suspension was placed in dialysis bag tied with glass tube and placed in a beaker containing $50 \mathrm{ml}$ of phosphate buffer (7.4) as receptor compartment. The samples are withdrawn from the medium at suitable intervals and analyzed for UV spectrophotometer.

\section{Osmotic shock}

The change in the vesicle size can be determined by osmotic studies. Proniosomal formulations are incubated with hypotonic, isotonic, hypertonic solutions for $3 \mathrm{~h}$. Then the changes in the size of vesicles in the formulations are viewed under optical microscopy.

\section{Stability studies}

Stability studies were carried out by storing the prepared proniosomes at various temperature conditions such as refrigeration temperature $\left(2-8^{\circ} \mathrm{C}\right)$, room temperature $\left(25^{\circ} \mathrm{C} \pm 0.5^{\circ} \mathrm{C}\right)$ and elevated temperature $\left(45^{\circ} \mathrm{C} \pm 0.5^{\circ} \mathrm{C}\right)$ from a period of $1 \mathrm{mo}$ to $3 \mathrm{mo}$.

According to International Conference on Harmonization (ICH) guidelines, reconstitution of dry prognosis powders should be studied for accelerated stability at $40{ }^{\circ} \mathrm{C} / 75 \%$ relative humidity as per international climatic zones and climatic conditions (WHO, 1996). For long term stability studies the temperature is $25{ }^{\circ} \mathrm{C} / 60 \% \mathrm{RH}$ for the countries in zone and II and for the countries in zone III and IV the temperature is $30{ }^{\circ} \mathrm{C} 65 \%$ Relative humidity (RH).

Table 1: Some of the research work carried out on proniosomes as drug carriers

\begin{tabular}{|c|c|c|c|c|}
\hline $\begin{array}{l}\text { S. } \\
\text { No. }\end{array}$ & Drug & $\begin{array}{l}\text { Therapeutic } \\
\text { category }\end{array}$ & Composition & Results \\
\hline 1. & Ketorolac [24] & NSAID & Span 60 , ethanol & $\begin{array}{l}\text { Span } 60 \text { provides higher drug flux across the skin } \\
\text { than tween } 20 .\end{array}$ \\
\hline 2. & Aceclofenac [25] & NSAID & Span, Tween, lecithin, cholesterol. & $\begin{array}{l}\text { The niosome dispersion acts specifically on } \\
\text { inflammatory sites and decreases inflammation. }\end{array}$ \\
\hline 3. & Flurbiprofen [26] & NSAID & Span $(20,40,60,80)$, ethanol & $\begin{array}{l}\text { Sustained anti-inflammatory activity } \\
\text { and dosing frequency. }\end{array}$ \\
\hline 6. & Estradiol [27] & Hormone & $\begin{array}{l}\text { Span }(40,60,85), \text { Tween }(20,40) \text {, } \\
\text { lecithin, cholesterol }\end{array}$ & $\begin{array}{l}\text { Encapsulation of proniosomes of span surfactant } \\
\text { showed a high value. }\end{array}$ \\
\hline 7. & Ritonavir[28] & Anti-retroviral & $\begin{array}{l}\text { Span }(20,40,60,80), \text { Tween } \\
(20,40,60,80) \text {, lecithin, cholesterol, } \\
\text { carbopol-934. }\end{array}$ & $\begin{array}{l}\text { Proniosomes sustained the release of drug over } 12 \\
\text { h. and reduces side effects. }\end{array}$ \\
\hline 8. & Valsartan [29] & $\begin{array}{l}\text { Angiotensin II } \\
\text { inhibitor }\end{array}$ & Span 40,60 , soya lecithin & $\begin{array}{l}\text { Improve oral bio availability and enhanced } \\
\text { permeation }\end{array}$ \\
\hline 10. & Cromolyn sodium [30] & Anti-inflammatory & Span, lecithin, cholesterol & Controlled drug release and improve aerosolization. \\
\hline 11. & Pioglitazone [31] & Anti-hypoglycemia & Span, lecithin, cholesterol & $\begin{array}{l}\text { Improve hypoglycemic effects by controlled release } \\
\text { of drug. }\end{array}$ \\
\hline 12. & Terconazole [32] & Anti-fungal & Surfactants, lecithin, cholesterol & Enhance mucoadhesive properties \\
\hline 13. & Benzocaine [33] & sedatives & Span $60 /$ cholesterol & Improve local anesthesia and controlled release \\
\hline 14. & Nateglinide [34] & Anti-diabetic & Span 60 , maltodextrin, cholesterol & Improve oral bioavailability. \\
\hline 15. & Simvastatin [35] & $\begin{array}{l}\text { HMG Co A } \\
\text { reductase inhibitor }\end{array}$ & Tween 20 , lecithin & $\begin{array}{l}\text { Enhance bioavailability and hypocholesterolemia } \\
\text { effect. }\end{array}$ \\
\hline
\end{tabular}




\section{Applications of proniosomes}

\section{Drug targeting}

\section{Applications in cardiology}

In the treatment of hypertension Proniosomes are used as carriers for the transdermal delivery of captopril. The proniosomal system extends the release of the drug in the body. Encapsulation of the drug is carried out using Sorbitan esters, Cholesterol and lecithin.

\section{Application in diabetes}

Furesamide proniosomes of skin permeation mechanism is performed in which span, soya; lecithin, diacetyl phosphate, and cholesterol were used. All findings suggest that the proniosomes serve as non-invasive delivery of furesamide [36].

\section{Anti-neoplastic treatment}

Most Anti-neoplastic drugs cause severe side effects. Niosomes can alter the metabolism; prolong circulation and half-life of the drug, thus decreasing the side effects of the drugs. In an unentrapped drug, study the proniosomal entrapment of Doxorubicin and Methotrexate (in two separate studies) showed beneficial effects, such as decreased rate of proliferation of the tumor and higher plasma levels accompanied by slower elimination. Also, proniosomes are one of the sterile drug delivery system that is widely used in cancer therapies.

\section{Hormonal therapy}

Proniosome are used for the delivery of levonorgestrel the emergency contraceptive. System was tested for particle size, encapsulation efficiency, stability study, in vivo and in vitro study. The Bioassay for pregestational activity was also performed. It included endometrial assay and blockade of development of corpora lutea [37].

\section{Delivery of peptide drugs}

Oral peptide drug delivery leads to breakdown of peptide and protein bonds [38]. Niosomes protect the peptides from gastrointestinal peptide break down. Vasopressin derivative entrapped in niosomes also showed increased stability

\section{Use in studying immune response}

Proniosomes are used in studying the immune response due to their immunological selectivity, low toxicity and greater stability. Niosomes and proniosomes are used to study the nature of the immune response produced by antigens.

\section{Niosomes carriers for haemoglobin}

Proniosomes can be used as carriers for hemoglobin within the blood [39]. The proniosomal vesicle is permeable to oxygen and hence can act as a carrier for hemoglobin in anemic patients.

\section{Transdermal drug delivery systems}

One of the most useful aspects of proniosomes is that they greatly enhance the uptake of drugs through the skin. Transdermal drug delivery using proniosomal technology is widely used in cosmetics. proniosome entrapped antibiotics are used topically to treat acne. The drug penetration through the skin in the form of proniosomes is greatly increased compared to un-entrapped drug.

Recently transdermal vaccines utilizing proniosomal technology is also being researched [40]. Proniosome can be utilized for topical immunization using tetanus toxoid. However, the current technology in proniosomes allows only a weak immune response and thus more research to be done in this field.

\section{Treatment of leishmaniasis}

Leishmaniasis is a disease in which a parasite of the genus Leishmania invades the cells of the liver and spleen. Commonly prescribed medication for the treatment are derivatives of antimony (antimonial), which in higher concentrations can cause cardiac, liver and kidney damage.

\section{Sustained release}

Proniosomes can be applied for Sustained release action of to drugs with low therapeutic index and low water solubility since those could be maintained in the circulation via niosomal encapsulation [41].

\section{CONCLUSION}

With recent advances in drug delivery systems proniosomes have gained pronounced recognition in the field of Novel drug delivery. Proniosomes have the potential to overcome the solubility and permeability problems of class II and IV drugs and have the capability to entrap both hydrophilic and hydrophobic drugs. Proniosomes are thought to be better candidates of drug delivery as compared to liposomes and niosomes due to various factors like cost, stability etc. Proniosomes are osmotically active and stable because they improve the stability of the entrapped rug during the delivery. Proniosomes are more effective for delivery of drugs through transdermal route, as they have the advantages like nontoxicity, effective modification of drug release and penetration enhancing effect of surfactants. Proniosomes are known to avoid many of the problems associated with either the aqueous noisome dispersion as problems of physical stability such as aggregation, fusion, and leakage. Proniosomes have the advantage of delivering drugs through various routes like oral, parenteral, dermal, transdermal, ocular, vaginal, mucosal pulmonary, and nasal effectively. Proniosomes are extensively employed in oral and transdermal delivery of a wide variety of drugs. Proniosomes are an effective tool for targeting of drugs and have the potential to provide better treatment than conventional drug delivery system.

\section{ACKNOWLEDGEMENT}

The authors are thankful to Shri Lavu Rathaiah garu, Chairman, Vignan group of institutions for providing the necessary facilities to carry out this review.

\section{FUNDING}

Nil

\section{AUTHORS CONTRIBUTIONS}

All the authors have contributed equally.

\section{CONFLICT OF INTERESTS}

\section{Declared none}

\section{REFERENCES}

1. Rao R, Kakar R, Anju G, Sanju N. Review on proniosomes: an emerging vesicular system in drug delivery and cosmetics. Der Pharmacia Lettere. 2010;2(4):227-39.

2. Sadanandan A, Boby Johns G, Samuel J, Raj P, Thomas N, Daisy PA, Carla B. A review on: proniosomes-An innovative approach to vesicular drug delivery system. World J Pharm Pharm Sci. 2017;6(3):1039-53.

3. Kakr R, Rao R, Goswami A, Nanda S, Saroha K. A review on: proniosmes-An emerging vesicular system in drug delivery and cosmetics. Der Pharm Lett. 2010;2:227-39.

4. Puglia C, Trombetta D, Venuti V, Saija A, Bonina F. Evaluation of in vivo topical anti-inflammatory activity of indometacin from liposomal vesicles. J Pharm Pharmacol. 2004;56(10):1225-32. doi: 10.1211/0022357044445, PMID 15482636.

5. Akhilesh D, Hazel G, Kamath J. Proniosomes-A propitious provesicular drug carrier. Int J Pharm Pharm Sci Res. 2011;1(3):98-103.

6. Song S, Tian B, Chen F, Zhang W, Pan Y, Zhang Q, Yang X, Pan W. Potentials of proniosomes for improving the oral bioavailability of poorly water-soluble drugs. Drug Dev Ind Pharm. 2015;41(1):51-62. doi: 10.3109/03639045.2013.845841, PMID 24111828.

7. Sudhamani T, Priyadarisini N, Radhakrishnan M. A review on: proniosomes-A promising drug carrier. Int J Pharm Technol Res. 2010;2(2):1446-54.

8. Akhilesh D, Faishal G, Kamath J. Comparative study of carriers used in proniosomes. Int J Pharm Chem Sci. 2012;1(1):164-73. 
9. Ijeoma F, Uchegbu SP, V Yas. Non-ionic surfactant-based vesicles (niosomes) in drug delivery. Int J Pharm. 1998;172(12):33-70.

10. Vyas SP, Khar RK. Review on: niosomes-targeted and controlled drug delivery novel carrier system, C.B.S [publication]. 1st ed; 2001;23:173-248

11. Giddi HS, Arunagirinathan MA, Bellare JR. Self-assembled surfactant nano-structures important in drug delivery: a review. Indian J Exp Biol. 2007;45(2):133-59. PMID 17375554.

12. Walve JR, Rane BR, Gujrathi NA. A review on: proniosomes-A surrogate carrier for improved transdermal drug delivery system. Int J Res Ayurveda Pharm. 2011;2:743-50.

13. Comelles F, Sanchez-Leal J, Gonzalez JJ. Influence of ionic surfactants on the formation of liquid crystals in oleic acid/glycol/water systems. J Surfact Deterg. 2007;10(3):13744. doi: $10.1007 / \mathrm{s} 11743-007-1023-9$.

14. Akhilesh D, Hazel G, Kamath JV. Review on: proniosomes-A propitious provesicular drug carrier. Int J Pharm Sci Res. 2011;1:98-103.

15. Jha AK, Kumar R, Kumar S, Jha SS. Vesicular system-carrier for drug delivery. Pharm Sin. 2011;2(4):192-202.

16. Triputianiludasi VP, Wankhade LM. Ingle, Sandeep Atram, Kiran K Tappar. A review on: proniosomes-A novel approach to vesicular drug delivery systems. 2012;3(1):1-6.

17. Kumari R, Verma K, Verma A, Yadav GK, Maurya SD. A review on proniosomes: a key to improved drug delivery. J Drug Deliv Ther. 2014;24:56-65.

18. Mishra A, Kapoor A, Bhargava S. A review on: proniosomal gel as a carrier for improved transdermal drug delivery. Asian J Pharm Life Sci. 2011;1:370-9.

19. Sankar V, Ruckmani K, Durga S, Jailani S. Proniosomes as drug carriers. Pak J Pharm Sci. 2010;23(1):103-7. PMID 20067875.

20. Kakkar R, Rao R, Kumar DN. A review on: formulation and characterization of valsartan proniosomes. Maejo Int J Sci Technol. 2011;5:146-58.

21. Keservani RK, Sharma AK, Ayaz MD. A review on novel drug delivery system for the vesicular delivery of drug by the niosomes. Int J Res Control Release. 2011;1:1-8.

22. Gupta R, kumar S, Gupta N, Kumar V, Prajapati SK, kumar A. A review on: the proniosomes development and optimization as a surrogated drug carrier for oral delivery of gliclazide. An Overview. 2014;3(9):275-80.

23. Pavala Rani N, Suryaprakashand TN, Senthamarai R. A review on: formulation and evaluation of rifampicin and gatifloxacinniosomes on logarithmic phase cultures of mycobacterium tuberculosis. Int J Pharmaciuetical Biol Sci. 2010;1:379-86.

24. Kapil S, Rao R, Saini V. A review on: preparation and evaluation of lornoxicamniosomal gel. Int Res J Pharm. 2012;3:378-83.

25. Kumar GP, Rajeshwarrao P. Nonionic surfactant vesicular systems for effective drug delivery- an overview. Acta Pharmaceutica Sinica B. 2011;1(4):208-19. doi: 10.1016/j.apsb.2011.09.002.

26. Alsarra IA, Hamed AY, Alanazi FK, El Maghraby GM. Vesicular systems for intranasal drug delivery. Neuromethods. 2010:175-203. doi: 10.1007/978-1-60761-529-3_8.
27. Solanki AB, Parikh JR, Parikh RH. Formulation and optimization of piroxicam proniosomes by 3-Factor, 3-level box-behnken design. AAPS PharmSciTech. 2007;8(4):E86. doi: 10.1208/pt0804086, PMID 18181547.

28. Verma P, Prajapati SK, Yadav R, Senyschyn D, Shea PR, Trevaskis NL. Single intravenous dose of novel flurbiprofenloaded proniosome formulations provides prolonged systemic exposure and anti-inflammatory effect. Mol Pharm. 2016;13(11):3688-99. 10.1021/acs.molpharmaceut.6b00504, PMID 27632682.

29. Fang JY, Yu SY, Wu PC, Huang YB, Tsai YH. In vitro skin permeation of estradiol from various proniosome formulations. Int J Pharm. 2001;215(1-2):91-9. doi: 10.1016/s03785173(00)00669-4, PMID 11250095.

30. Nimbalwar M, Upadhye K, Dixit Gouri. Fabrication and evaluation of ritonavir proniosomal transdermal gel as a vesicular drug delivery system. Pharmacophore. 2016;7(2):82-95.

31. Gurrapu A, Jukanti R, Bobbala SR, Kanuganti S, Jeevana JB. Improved oral delivery of valsartan from maltodextrin based proniosome powders. Adv Powder Technol. 2012;23(5):58390. doi: 10.1016/j.apt.2011.06.005.

32. Abd-Elbary A, El-Laithy HM, Tadros MI. Sucrose stearate-based proniosome-derived niosomes for the nebulisable delivery of cromolyn sodium. Int J Pharm. 2008;357(1-2):189-98. doi: 10.1016/j.ijpharm.2008.01.056, PMID 18339494.

33. Shukr MH, Eltablawy NA. Development and optimization of novel controlled-release pioglitazone provesicular powders using $3^{2}$ factorial design. Drug Deliv Transl Res. 2015;5(1):5162. doi: 10.1007/s13346-014-0215-x, PMID 25787339.

34. M Abdou E, M Ahmed N. Terconazole proniosomal gels: effect of different formulation factors, physicochemical and microbiological evaluation. J Pharm Drug Deliv Res 2016;05(1). doi: 10.4172/2325-9604.1000144.

35. Abd El-Alim SH, Kassem AA, Basha M. Proniosomes as a novel drug carrier system for buccal delivery of benzocaine. J Drug Deliv Sci Technol. 2014;24(5):452-8. doi: 10.1016/S17732247(14)50087-1.

36. Sahoo RK, Biswas N, Guha A, Kuotsu K. Maltodextrin based proniosomes of nateglinide: bioavailability assessment. Int J Biol Macromol. 2014;69:430-4. doi: 10.1016/j.ijbiomac.2014.05.075, PMID 24909314.

37. Shaker DS, Nasr M, Mostafa M. Bioavailability and hypocholesterolemic effect of proniosomal simvastatin for transdermal delivery. Int J Pharm Pharm Sci. 2013;5:344-51.

38. Gupta A, Prajapati SK, Balamurugan M, Singh M, Bhatia D. Design and development of a proniosomal transdermal drug delivery system for captopril. Trop J Pharm Res. 2007;6(2):687-93. doi: 10.4314/tjpr.v6i2.14647.

39. Vora B, Khopade AJ, Jain NK. Proniosome based transdermal delivery of levonorgestrel for effective contraception. J Control Release. 1998;54(2):149-65. doi: 10.1016/s01683659(97)00100-4, PMID 9724902.

40. Akhilesh D, Bini KB, Kamath JV. Comparative study of carriers used in proniosomes. Int J Pharm Chem Sci. 2012;3:6-12.

41. Moser P, Marchand Arvier M, Labrude P, Handjanivila RM, Vignerson C. Niosomes d hemogolbine. I. Preparation, properties physicochimiques et oxyphoriques, Stabilite. Pharm Acta Helv. 1989;64(7):192-202. 